Special Issue: Diabetic Nephropathy

\title{
Resistant Hypertension in Diabetes Mellitus
}

\author{
Pedro Armario ${ }^{1,2 *}$, Pedro Blanch ${ }^{1,3}$, Pere Castellanos ${ }^{1,2}$, Raquel Hernandez del Rey ${ }^{1,2}$, Carlos Jericó $^{1,2}$, Oana \\ Rap $^{1,4}$, Carmen Martin-Castillejos ${ }^{1}$, Antonio Mestrón ${ }^{1,5}$ and LLuis Vila ${ }^{1,5}$ \\ ${ }^{1}$ Vascular Risk Area. Hospital Moisès Broggi- Consorci Sanitgari Integral, University of Barcelona, Spain \\ ${ }^{2}$ Department of Internal Medicine- Hospital Moisès Broggi- Consorci Sanitari Integral, University of Barcelona, Spain \\ ${ }^{3}$ Department of Cardiology -Hospital Moisès Broggi- Consorci Sanitari Integral, University of Barcelona, Spain \\ ${ }^{4}$ Department of Nephrology- Hospital Moisès Broggi- Consorci Sanitari Integral, University of Barcelona, Spain \\ ${ }^{5}$ Department of Endocrinology -Hospital Moisès Broggi- Consorci Sanitari Integral, University of Barcelona, Spain
}

Received: May 18, 2015; Accepted: May 29, 2015; Published: June 10, 2015

*Corresponding author: Pedro Armario, Vascular Risk Area and Department of Internal Medicine Hospital Mosès Broggi Sant Joan Despi- Consorci Sanitarilntegral, Jacint Verdaguer, 90. 08970 Sant Joan Despi. Barcelona, University of Barcelona, Tel: + $34935531200: 8602 ;$ Fax: + 3493 553 12 17; Email: pedro.armario@sanitatintegral.org

\begin{abstract}
Diabetes Mellitus (DM) confers an increase of cardiovascular risk, independently from other conventional risk factors. The risk of cardiovascular events is 4-fold higher in patients with both diabetes and hypertension, compared with the normotensive controls. Compared with data from the general population or hypertensive individuals, a higher frequency of Resistant Hypertension (RH) has been observed in subjects with type 2 diabetes. Moreover, subjects with resistant hypertension had a higher prevalence of diabetes as compared with patients treated and controlled with three or less drugs.

In this review, the burden of RH in subjects with diabetes and the ratio between benefit and risk of spironolactone according to the renal function and or Hyperkalemia has been examined. In addition, this review focus in the possible role of new non-pharmacological techniques used in recent years in the control the $\mathrm{RH}$, and its effect on office blood pressure and the most controversial and heterogeneous effects on ambulatory BP. Some studies have shown promising results on the metabolism of glucose and insulin repetition, but these promising results need to be confirmed in large randomized studies.
\end{abstract}

Keywords: Resistant Hypertension; Diabetes; Spironolactone

\section{Introduction}

A great number of clinical trials have shown the benefits of reducing Blood Pressure (BP) to prevent cardiovascular morbidity and mortality and these are directly proportional to the BP levels achieved. Despite this, BP is poorly controlled in most countries. Several factors have been associated with poor control, some of which involve the characteristics of the patients themselves, such as socioeconomic factors, poor unsuitable lifestyles, but other factors are related to hypertension or to associated comorbidity' and the control rate is even lower in highrisk hypertensive patients such as diabetic patients and patients with chronic kidney disease [1,2]. But uncontrolled hypertension and Resistant Hypertension (RH) are not synonymous.
Uncontrolled hypertension includes patients who have not met targets because they failed to adhere to treatment or who are not treated adequately.

$\mathrm{RH}$ is defined as office blood pressure that remains above the goal despite the concurrent use of 3 antihypertensive agents, at full doses, one of them being a diuretic [3]. In addition, the term RH has been suggested for those patients with true RH and values above normal limits, after a careful exclusion of secondary causes, and in whom adequate adherence to medication has been evaluated $[4,5]$

\section{Prevalence and Incidence of Resistant Hypertension}

Data about the prevalence of RH have been reported from the Spanish ABPM Registry, the epidemiological community and the National Health and Nutrition Examination Survey (NHANES) from the United States, to establish that the prevalence of RH in treated hypertensive population is around $12-14 \%[6,7]$. This condition is of clinical importance, because it is associated with a worse prognosis.

The prevalence of $\mathrm{RH}$ is higher in a number of clinical conditions such as obesity, diabetes mellitus, or chronic renal disease or target organ damage $[4,8]$.

In a retrospective cohort study of 205,750 patients with incident hypertension, $1.9 \%$ developed $\mathrm{RH}$ within a median of 1.5 years from their initial treatment $(0.7$ cases per 100 person-years of follow-up). Over 3.8 years of median follow-up, and after adjustment for patients and clinical characteristics, cardiovascular event rates were significantly higher in $\mathrm{RH}$ patients [9].

Role of Ambulatory Blood Pressure Monitoring (ABPM) in Resistant Hypertension

The definition of $\mathrm{RH}$ is based on office measurements. 
However, the use of ABPM has allowed for the recognition of pseudoresistant hypertension. It is estimated that more than a third of patients with suspected RH have white coat or isolated office RH, showing a normal daytime or 24-hour ABPM values ${ }^{6}$, These subjects are characterized by a lower prevalence of target organ damage $[10,11]$. On the other hand, several prospective studies have shown a better prognosis in patients with pseudoresistant hypertension compared with subjects with true RH [12-14].

Furthermore, ABPM add some information on the circadian BP pattern. The non dipper or risers pattern are more frequent in subjects with true $\mathrm{RH}$ than in subjects with white coat $\mathrm{RH}$ and there is wide evidence on the value of nocturnal BP as the parameter that best correlates with organ target damage [15], and as an independent predictor of the occurrence of cardiovascular disease during follow-up[16]. On the other hand, the group of Muxfeldt et al. [17] in a prospective study of 547 subjects with $\mathrm{RH}$ followed during 4.7years, have shown the prognosis of $24 \mathrm{~h}$-ambulatory arterial stiffness index. Therefore, the role of ABPM is central both in the initial diagnosis of subjects with $\mathrm{RH}$ and during the follow-up.

\section{Diabetes and Resistant Hypertension}

DM confers an increase of cardiovascular risk. A collaborative meta-analysis of 102 prospective studies [18] has shown that DM confers about a two-fold excess risk for coronary heart disease, major stroke subtypes, and deaths attributed to vascular causes, independently from other conventional risk factors. Hypertension is present in more than $50 \%$ of patients with DM and contributes significantly to both microvascular and macrovascular disease. The risk of cardiovascular events is 4-fold higher in patients with both DM and hypertension, compared with the normotensive controls [19]. DM and hypertension share several pathophysiological mechanisms including inappropriate activation of the renin-angiotensin-aldosterone system, increased sympathetic nervous system activation, insulin resistance and hyperinsulinemia, oxidative stress, inflammation, impaired insulin-mediated vasodilatation, and abnormal renal processing of sodium $[19,20]$. On the other hand, some research has suggested a direct association between DM and primary hyperaldosteronim. Umpierrez et al. [21] observed a prevalence of $14 \%$ of primary aldosteronism in diabetic patients with poorly uncontrolled hypertension taking $\geq 3$ antihypertensive agents.

Compared with data from the general population or hypertensive individuals, a higher frequency of $\mathrm{RH}$ has been observed in subjects with type 2 diabetes. The RIACE study enrolled 15,773 patients consecutively visiting 19 diabetes clinics during the years 2007-2008, and RH was detected in 2,363 subjects $(15 \%$ of the whole RIACE cohort [22], $17.4 \%$ of hypertensive individuals, and $21.2 \%$ of treated hypertensive patients). Moreover, subjects with RH from the Registry of the Spanish Society of Hypertension [11] have shown a high prevalence of DM (38.6\%), and metabolic syndrome (63.8\%). In an analysis of 27,897 hypertensive subjects [23], those with $\mathrm{RH}$ had a higher prevalence of DM as compared with patients treated and controlled with three or less drugs (35.1\% vs $18.8 \%$ respectively).

The burden of $\mathrm{RH}$ in people with type 1 diabetes has also been examined. A cross-sectional study[24] including a nationally representative cohort of patients with type 1 diabetes $(n=3,678)$ from the Finnish Diabetic Nephropathy Study in Finland has shown that the prevalence of $\mathrm{RH}$ was $1.2 \%$ in the normoalbuminuric, $4.7 \%$ in the microalbuminuric, $28.1 \%$ in the macroalbuminuric, $36.6 \%$ in the dialysis and $26.3 \%$ in the kidney transplant groups.

\section{Treatment of Resistant Hypertension in Diabetic Patients}

Following are some steps in the management of hypertension difficult to control in diabetic patients, being necessary to confirm a good adherence to lifestyle changes and drug treatment, exclude secondary causes of hypertension, and confirm the lack of control by ambulatory BP-24h (Figure 1 and Table 1).

The definition of RH implies that one of the 3 drugs must be a diuretic, since the resistance of hypertension is often due, at least in part to inadequate control of volume expansion. Studies have shown that diuretic use is associated with improved BP control. The main classes of diuretic agents used in hypertension are thiazide or thiazide-like diuretics or loop diuretics in patients with a reduction of renal function (glomerular filtration rate $<40 \mathrm{~mL} / \mathrm{min}$ )[25] Not all thiazide diuretics are equally efficacious. Chlortalidone, a longer-acting thiazide-like diuretic and indapamide have been recommended, especially in patients with poor control of hypertension [26]. A systematic review and meta-analysis [27] has shown that the use of thiazide-like diuretics was associated with additional risk reduction of $12 \%$ for cardiovascular events, and the incidence of adverse events was comparable among thiazide and thiazide-like diuretics.

Spironolactone is a nonselective antagonist of aldosterone and potassium-sparing diuretic. Despite its short half-life, the onset of action of aldosterone is slow, since it usually begins 48 hours after the initial dose, and the maximum effect on BP is observed after 3-4 weeks, and persists for at least one week after the suppression of the same, due to the presence of active metabolites. In recent years, evidence has been accumulated on the role of spironolactone at a dose of 25-50 mg per day in the management of RH. Although most of these studies were open, uncontrolled, or retrospective analyses, a significant reduction in BP (20-25 mm Hg systolic and 10-12 mm Hg for diastolic BP) was observed. This reduction was higher than would be expected by the simple addition of another antihypertensive [28]. A metaanalysis has been recently published [29] and 13 eligible studies were identified involving a total of 2,640 patients ( 3 randomized controlled trials and 10 observational studies without a control group). In controlled studies, there was a reduction in mean systolic and diastolic BP of -16.5 (95\% confidence interval: -30.0 to $-3.0 \mathrm{~mm} \mathrm{Hg}$ ) and $-4.1(95 \% \mathrm{CI}-7.8$ to $-0.32 \mathrm{~mm} \mathrm{Hg}$ ), respectively. In this meta-analysis, it has been observed that the use of an aldosterone antagonist was associated with a mild but significant increase in serum potassium and creatinine. Diabetic 


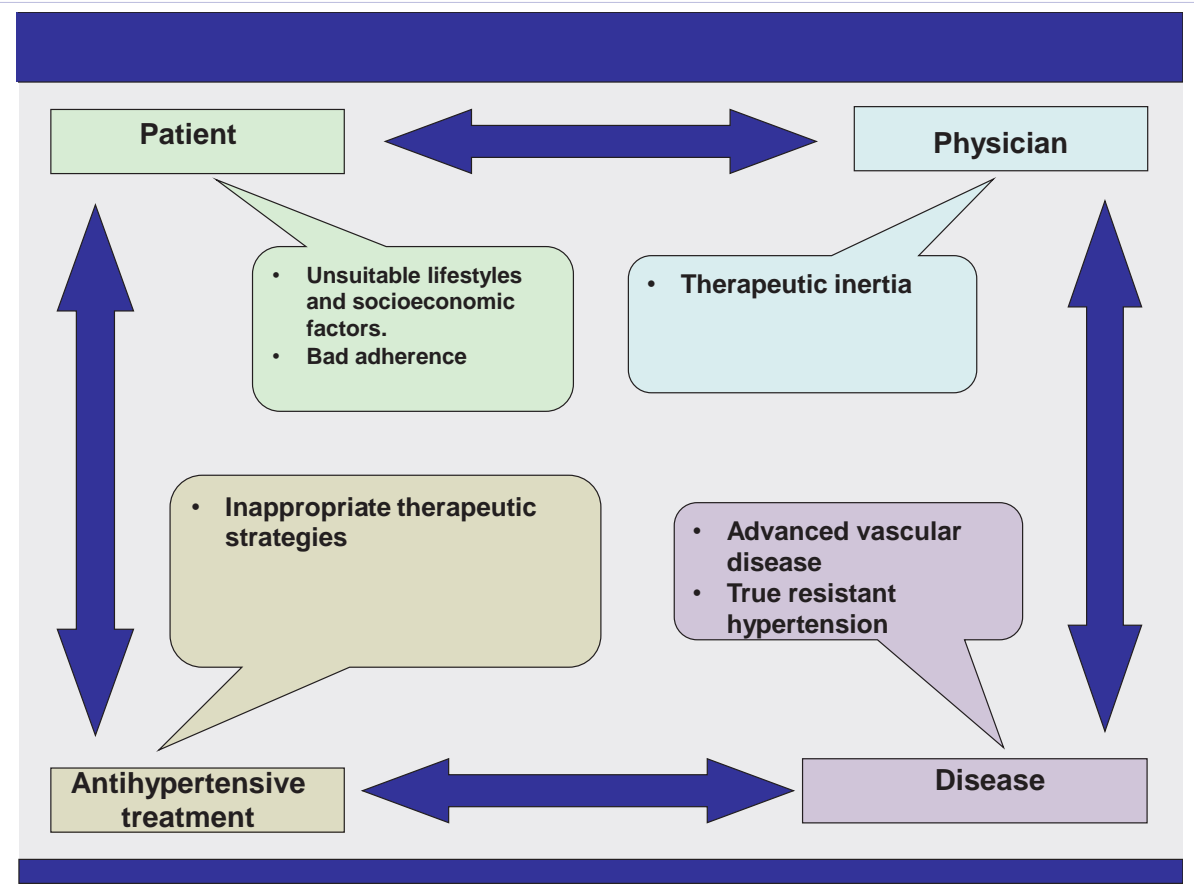

Figure 1: Clinical situations associated with difficult-to-control hypertension.

Table 1: Recommended steps in the management of resistant hypertension in diabetic patients.
1. Improve lifestyle changes
2. To evaluate adherence
3. To exclude pseudoresitance hypertension with ambulatory blood pressure monitoring
4. Re-check for secondary causes,
5. Optimize pharmacological therapy
6. Consider new strategies for the management of resistant hypertension: renal sympathetic denervation or stimulation of the carotid baroreceptors.

patients could develop hyperkalaemia during treatment with an angiotensin-converting enzyme inhibitor or angiotensin receptor blocker in combination with low doses of spironolactone, more frequently than other non-diabetic hypertensive patients. However, low dose spironolactone exerts a significant BP and urinary albumin creatinine ratio thereby lowering the effects in high-risk patients with RH and type 2 diabetes mellitus [30]. Oxlund et al. [31], in a multicentre, double-blind, randomized, placebo-controlled trial study of 112 patients with RH, confirmed these results, and they observed that adverse events during the treatment with a low dose of spironolactone in these diabetic patients with RH and near normal renal function were infrequent and no unexpected adverse effects were seen.

RH is frequently associated with chronic kidney disease, but in this population the frequency of occurrence of hyperkalaemia during treatment with spironolactone is higher, especially when the estimated Glomerular Filtration Rate (eGFR) is $<45 \mathrm{ml} /$ $\min / 1.73 \mathrm{~m}^{2}$, and this treatment is not recommended when the GFR is $<30 \mathrm{ml} / \mathrm{min} / 1.73 \mathrm{~m}^{2}$. Finally, some patients do not respond to spironolactone, and other therapeutic regimens can be used, based more on clinical experience than on the results of controlled studies.

\section{New Strategies for the Management of RH}

Sympathetic overactivity is seen in a wide array of medical conditions including RH. The contribution of renal afferent and efferent sympathetic activity on the development and progression of hypertension has been demonstrated in both preclinical studies and humans in various models of hypertension, myocardial infarction and chronic renal disease [32].

In recent years, two new techniques have been developed and evaluated in managing RH: renal sympathetic denervation and stimulation of the carotid baroreceptors.

Renal denervation therapy: The European Societies of Hypertension [33] and Cardiology [34] have been positioned on the role of this technique in the management of $\mathrm{RH}$, establishing a series of indications and recommendations. On the other hand, in the last 2013 Guidelines of the European Society of Hypertension and European Society of Cardiology [35], it is recommended that its use may be indicated in selected cases, always when there is a lack of response to antihypertensive treatment, but according to the current data, the definite role and indications of this treatment are not clear. There is a scientific rationale for the procedure, and the magnitude of BP reduction was significant, 
but the effects of this procedure on blood pressure levels obtained during the ABPM are less clear [36]. Some argued that the absence of a positive finding in Symplicity HTN-3 was mainly related to adding a sham procedure and blinding of patients, and others tried to provide other explanations [37].

Baroreflex activation therapy: Treatment based on baroreceptor activation is consistent with electrical stimulation located in the carotid sinus technique, resulting in reduced sympathetic outflow to the heart, vascular system and kidneys as well as an increase in parasympathetic tone [38]. Today, we have the results of two studies: the Device-Based Therapy in Hypertension trial (Debut-TH) [39] and the Rheos Pivotal Trial $[40,41]$, which have shown promising results, although some complications directly related to the surgical procedure were observed. More recently, a system of baroreflex activation of second generation has been introduced, and 33 patients with RH were evaluated in 7 centers in Europe and Canada with a baseline BP of $172 / 100 \mathrm{~mm} \mathrm{Hg}$, and in which a reduction in BP was observed at 6 months of $26 / 12 \mathrm{~mm} \mathrm{Hg}$ [42]. During the procedure, only 3 minor complications appeared within the first 30 days of implanting the device, and all were resolved without sequelae.

Some studies have shown that renal denervation improves glucose metabolism, and insulin sensitivity in addition to significantly reducing blood pressure in resistant hypertensive patients $[43,44]$, but these promising results need to be confirmed in large scale, randomized studies.

In summary, RH is highly prevalent in patients with diabetes and contributes to increased morbidity and mortality. Spironolactone a low doses can improve the control rate of RH. However it should be used with caution in patients with diabetes because of the risk of hyperkalemia. Interesting perspectives could be open in the treatment of RH with renal denervation therapy and baroreflex activation therapy, but its role in diabetic patients with RH need to be confirmed in large scale, randomized studies.

\section{Acknowledgment}

We would like to thank Kathryn O'Connor for the review of the manuscript

\section{References}

1. Oliveras A, Schmieder RE. Clinical situations associated with difficultto-control hypertension. J Hypertens. 2013; 31 Suppl 1:S3-8. doi: 10.1097/HJH.0b013e32835d2af0.

2. Armario P, Waeber B. Therapeutic strategies to improve control of hypertension. J Hypertens. 2013; 31 Suppl 1:S9-12. doi: 10.1097/ HJH.0b013e32835d2c6c.

3. Calhoun DA, Jones D, Textor S, Goff DC, Murphy TP, Toto RD, et al. Resistant hypertension: diagnosis, evaluation, and treatment: a scientific statement from the American Heart Association Professional Education Committee of the Council for High Blood Pressure Research. Hypertension. 2008; 51(6):1403-19. doi: 10.1161/ HYPERTENSIONAHA.108.189141.

4. Oliveras A, de la Sierra A. Resistant hypertension: patient characteristics, risk factors, co-morbidities and outcomes. J Hum Hypertens 2014; 28:213-217. doi:10.1038/jhh.2013.77.

5. Vongpatanasin W. Resistant hypertension. A review of diagnosis and management. JAMA. 2014; 311(21):2216-2224. doi: 10.1001/ jama.2014.5180.

6. de la Sierra A, Segura J, Banegas JR, Gorostidi JR, de la Cruz , Armario P, et al. Clinical features of 8295 patients with resistant hypertension classified on the basis of ambulatory blood pressure monitoring. Hypertension. 2011; 57(5):898-902. doi: 10.1161/ HYPERTENSIONAHA.110.168948.

7. Persell SD. Prevalence of resistant hypertension in the United Sates, 2003-2008. Hypertension. 2011; 57(6):1076-1080. doi: 10.1161/ HYPERTENSIONAHA.111.170308.

8. Gijón-Conde T, Graciani A, Banegas JR. Resistant hypertension; demography and clinical characteristics in 6,292 patients in a primary health care setting. Rev Esp Cardiol (Engl Ed). 2014; 67(4):270-276. doi: 10.1016/j.rec.2013.09.027.

9. Daugherty SL, Powers JD, Magid DJ, Tavel HM, Masoudi FA, Margolis $\mathrm{KL}$, et al. Incidence and prognosis of resistant hypertension is hypertensive patients. Circulation. 2012; 125(13):1635-42. doi: 10.1161/CIRCULATIONAHA.111.068064.

10. Oliveras A, Armario P, Hernández-Del Rey R, Arroyo JA, Poch E, Larrousse M, et al. Urinary albumin excretion Sierra is Associated With true resistant hypertension. J Hum Hypertens. 2010; 24(1):2733. doi: $10.1038 /$ jhh.2009.35.

11. Armario P, Oliveras A, Hernández del Rey R, Ruilope LM, de la Sierra A, on behalf of the Research Group Registry refractory hypertension of the Spanish Society of Hypertension / Spanish League for the Fight Against Hypertension (ESH -LELHA). Prevalence of organ damage and metabolic alterations in refractory hypertension (in spanish). Med Clin (Barc). 2011; 137(10):435-439. doi: 10.1016/j.medcli.2011.02.035.

12. Redon J, Campos C, Narciso ML, Rodiciol JL, Pascual JM, Ruilope LM. Prognostic value of ambulatory blood pressure monitoring in refractory hypertension: a prospective study. Hypertension. 1998; 31(2):712-718.

13. Pierdominico SD, Lapenna D, Bucci A, Di Tommaso R, Di Mascio R, Manente BM, et al. Cardiovascular outcome in hypertensive patients Treated with respond, masked, false resistant and true resistant hypertension. Am J Hypertens 2005; 18(11):1422-1428.

14. Salles GF, Cardoso CRL, Muxfeldt ES. Prognostic Influence of office and ambulatory blood pressure in resistant hypertension. Arch Intern Med. 2008; 168(21):2340-2346. doi: 10.1001/archinte.168.21.2340.

15. Oliveras A, Wardrobe P, Martell-Clarós N, Ruilope LM, de la Sierra A, on behalf of the Spanish Society of Hypertension-Resistant Hypertension Registry. Urinary albumin excretion is Associated With nocturnal systolic blood pressure in resistant hypertension. Hypertension 2011; 57:556-560. doi: 10.1161/HYPERTENSIONAHA.110.165563.

16. de la Sierra A, Banegas JR, Segura J, Gorostidi M, Ruilope LM. Ambulatory blood pressure monitoring and development of cardiovascular events in high-risk patients included in the Spanish ABPM Registry. J Hypertens. 2012; 30(4):713-9. doi: 10.1097/ HJH.0b013e328350bb40.

17. Muxfeldt ES, Cardoso CRL, Dias VB, Nascimento ACM, GF Dalles. Prognostic of ambulatory arterial stiffness index have in resistant hypertension. J Hypertens. 2010; 28(7):1547-1553. doi: 10.1097/ HJH.0b013e328339f9e5.

18. The Emerging Risk Factors Collaboration. Diabetes mellitus, 
fasting blood glucose concentration, and risk of vascular disease: a collaborative meta-analysis of 102 prospective studies. Lancet. 2010; 375(9733):2215-2222. doi: 10.1016/S0140-6736(10)60484-9.

19. Lastra G, Syed S, Kurukulasuriya LR, manrique C, Sowers JR. Type 2 diabetes mellitus and hypertension: an update. Endrocinol Metab Clin North Am 2014; 43(1):103-122.

20. Baylis G, Weinrauch LA, D`Ella JA. Resistant hypertension in diabetes mellitus. Curr Diab Rep 2014; 14:516. Doi. 10.1007/s11892-0140516-y.

21. Umpierrez GE, Cantey P, Smiley D, Palacio A, Tempon D, Luster $\mathrm{H}$, et al. Primary aldosteronism in diabetic subjects with resistant hypertension. Diabetes Care. 2007; 30(7):1699-1703.

22. Solini A, Zoppini G, Orsi E, Fondelli C, Trevisan R, Vedovato M, et al. Resistant hypertension in patients with type 2 diabetes: clinical correlates and association with complications. J Hypertens. 2014; 32(12):2401-2410; discussion 2410. doi: 10.1097/ HJH.0000000000000350.

23. de la Sierra A, Banegas JR, Oliveras A, Gorostidi M, Segura J, de la Cruz $\mathrm{JJ}$, et al. Clinical differences between resistant hypertensives and patients treated and controlled with three or less drugs. J Hypertens. 2012; 30(6):1211-1216. doi: 10.1097/HJH.0b013e328353634e.

24. Lithovis R, Harjutsalo V, Forsblom C, Saraheimo M, Groop PH FinnDiane Study Group. Antihypertensive treatment and resistant hypertension in patients with type 1 diabetes by stages of diabetic nephropathy. Diabetes Care. 2014; 37(3):709-717. doi: 10.2337/ dc13-2023.

25. Armario P, Oliveras A, de la Sierra A, Resistant hypertension (in Spanish). Rev Clin Esp (Barc) 2013; 213:388-393.

26. Roush GC, Ernst ME, Kostis JB, Tandon S, Sica DA. Head-tohead comparisons of hydrochlorothiazide with indapamide and chlortalidone. Antihypertensive and metabolic effects. Hypertension. 2015; 65(5):1041-1046. doi: 10.1161/ HYPERTENSIONAHA.114.05021.

27. Olde Engnerink RHG, Frenkel WJ, Van den Bogaard B, Brester LM, Vogt L , Van de Born BJH. Effects of thiazide-type and thiazide-like diuretics on cardiovascular events and mortality. Systematic review and meta-analysis. Hypertension. 2015; 65(5):1033-1040. doi: 10.1161/ HYPERTENSIONAHA.114.05122.

28. Glicklich D, Frishman WH. Drug therapy of apparent treatmentresistant hypertension: focus on mineralcorticoid receptor antagonists. Drugs 2015; 75:473-485. doi: 10.1007/s40265-0150372-3.

29. Liu G, Zheng XX, Xu YL, Lu J, Hui RT, Huang XH. Effect of aldosterone antagonists on blood pressure in patients with resistant hypertension: a meta-analysis. J Hum Hypertens. 2015; 29(3):159-166. doi: 10.1038/ jhh.2014.64.

30. Rossing K, Schjoedt KJ, Smidt UM, Boonsma F, Parving HH. Beneficial effects of adding spironolactone to recommended antihypertensive treatment in diabetic nephropathy: a randomized, double-masked, cross-over study. Diabetes Care. 2005; 28(9):2106-2112.

31. Oxlund CS, Henrikssen JE, Tarnow L, Schousboe K, Gram J, Jacobsen IA. Low dose spironolactone reduces blood pressure in patients with resistant hypertension and type 2 diabetes mellitus: a double blind randomized clinical trial. J Hypertens. 2013; 31(10):2094-2102. doi: 10.1097/HJH.0b013e3283638b1a.

32. Grassi G, Serravalle G, Brambilla G, Mancia G. The sympathetic nervous system and new nonpharmacologic Approaches to treating hypertension: a focus on renal denervation. Can J Cardiol. 2012; 28(3):311-317. doi: 10.1016/j.cjca.2011.11.005.

33. Schmieder RE, Redon J, Grassi G, Kjeldsen SE, Mancia G, Nasrkiewicz $\mathrm{K}$, et al. ESH Position Paper: renal denervation- an interventional therapy of resistant hypertension. J Hypertens. 2012; 30(5):837-841. doi: 10.1097/HJH.0b013e328352ce78.

34. Mahfoud F, Lüscher TF, Andersson B, Baumgartner I, Cifkova R, DiMario C, et al. Expert consensus document from the European Society of Cardiology on catheter-based renal denervation. Eur Heart J. 2013; 34(28):2149-2157. doi: 10.1093/eurheartj/eht154.

35. Mancia G, Fagard R, Narkiewicz K, Redon J, Zanchetti A, Böhm M et al. 2013 ESH / ESC Guidelines for the management of arterial hypertension. The Task Force for the management of arterial hypertension of the European Society of Hypertension (ESH) and the European Society of Cardiology. J Hypertens 2013; 31: 1281-1357.

36. Natham S, Bakris GL. The future of renal denervation in resistant hypertension. Curr Hypertens Rep. 2014; 16(12):494. doi: 10.1007/ s11906-014-0494-0.

37. Mahfoud F, Lüscher TF. Renal denervation: simply trapped by conmplexity? Eur Heart J 2015; 36:199-202.

38. Fernandez G, Lee JA, Liu LC, Gassler JP. The baroreflex in hypertension. Curr Hypertens Rep. 2015; 17(4):531. doi: 10.1007/s11906-0140531-z.

39. Scheffers IJ, Kroon AA, Schmidli J, Jordan J, Tordoir JJM, Mohaupt MG, et al. Novel baroreflex activation therapy in resistant hypertension. J Am Coll Cardiol. 2010; 56(15):1254-1258. doi: 10.1016/j. jacc.2010.03.089.

40. Bisognano JD, Bakris G, Nadim MK, Sanchez L, Kroon AA, Schafer $\mathrm{J}$, et al. Baroreflex activation therapy lowers blood pressure in patients with resistant hypertension: results from the double-blind, randomized, placebo-controlled pivotal trial Rheos. J Am Coll Cardiol. 2011; 58(7):765-773. doi: 10.1016/j.jacc.2011.06.008.

41. Bakris GL, Nadim MK, Haller H, Lovett EG, Schafer JE, Bisognano JD. Baroreflex activation therapy Provides durable benefit in patients with resistant hypertension: results of long-term follow-up in the Rheos Pivotal Trial. J Am Soc Hypertens. 2012; 6(2):152-158. doi: 10.1016/j.jash.2012.01.003.

42. Hoppe UC, Brandt MC, Wachter R, Beige J, Rump LC, Kroon AA, et al. Minimally invasive system for baroreflex activation therapy lowers blood pressure chronically With pacemaker-like safety profile: results from the trial neo Barostim. J Am Soc Hypertens. 2012; 6(4):270-276. doi: 10.1016/j.jash.2012.04.004.

43. Mahfoud F, Schlaich M, Kindermann I, Ukena C, Cremers B, Brandt MC, et al. Effect of renal sympathetic denervation on glucose metabolism in patients with resistant hypertension. A Pilot Study. Circulation. 2011; 123(18):1940-1946. doi: 10.1161/CIRCULATIONAHA.110.991869.

44.Grassi G. Renal denervation in cardiometabolic disease: concepts, achievements and perspectives. Nutr Metab Cardiovasc Dis. 2013; 23(2):77-83. doi: 10.1016/j.numecd.2012.09.004. 